\title{
The research on the transition of green agriculture to the industrialization path of supply-side reform
}

\author{
Dan $\mathrm{Su}^{1, \text { a }}$ \\ ${ }^{1}$ Ordos Institute of Technology, Inner Mongolia, 017000
}

\begin{abstract}
Under the background of the steady progress of the structural reform of the agricultural supply side, the rural ecological agriculture in the transition stage is faced with a series of bottlenecks and problems such as the lag of production technology renewal, the single management mechanism and the aggravation of environmental degradation. It is difficult to effectively form a new form of green, coordinated and sustainable development. Therefore, we should make full use of the favorable conditions such as policy support and institutional guarantee given by the structural reform of the agricultural supply side, and introduce efficient and innovative production and management models around the industrial upgrading, so as to promote the lowcarbon, intensive and diversified transformation of the existing ecological agriculture operation system.
\end{abstract}

\section{Introduction}

Through the integration of traditional agricultural production mode and modern science and technology, based on the management mode of ecological economics, green agriculture has become one of the core powers sources for scientific development of agricultural resources, curbing the trend of rural ecological environment destruction and accelerating the development of agricultural modernization. Driven by the wave of agricultural supply-side structural reform, green agriculture has gradually established a specialized, integrated and diversified industrial development system by strengthening market-oriented operation and seeking large-scale and intensive operation. TRestricted by such factors as unscientific planning, relatively extensive transportation management and the need to improve the degree of market development ${ }^{1}$. At present, while improving the production capacity and optimizing the industrial structure of green agriculture in China, there are also many problems such as excessive development, abuse of pesticides, and expansion of non-point source pollution. However, restricted by factors such as unscientific planning, relatively extensive transportation management and the degree of marketization development to be improved, green agriculture in China currently has many problems such as excessive development, pesticide abuse and expansion of non-point source pollution while improving production capacity and optimizing industrial structure. Therefore, on the basis of effective docking supply-side structural reform, we should steadily promote low-carbon production, green management and scientific management of green agriculture, and truly generate a new form of organic integration of resource development, environmental protection and economic development.

\section{Socio-economic significance of green agricultural industrialization transformation}

\subsection{Produce large-scale, standardized subdivision industry, further increase the economic volume of rural society.}

For a long time, the self-sufficient and relatively extensive small-scale peasant economy has always occupied the dominant position of China's traditional agricultural system, which has seriously hindered the large-scale and deep-level development and utilization of agricultural resources, reduced the conversion rate of economic benefits, and greatly restricted the consumption demand of rural society, resulting in the basic barrier the modernization of agriculture. As green agriculture has gradually become an independent and complete industrial type, the traditional agricultural production and management mode, which was originally scattered, inefficient and lack of market competitiveness, has begun to be replaced by a large-scale, standardized and efficient modern agricultural operation mechanism. Full integration of land, labor and other regional, crossregional advantages of resources to a more environmentally friendly, effective and convenient specialized production management, and constantly improve the conversion rate between production factors and economic benefits, subdivided from production, processing, marketing, operation and other aspects, led to a large number of local rural surplus labor employment, entrepreneurship, effectively increase the income channels and income of this group, so that the rural society's huge consumer demand, development vitality

\footnotetext{
a topsudan@163.com; topsudan@oit.edu.cn
} 
has been further released, thereby increasing the volume of rural economy. The key technology of agricultural and rural ecological civilization and green development standard system construction in China mainly focuses on agricultural green development, rural living environment, rural ecological protection and restoration, and rural greening and green industry. Please look at Figure 1

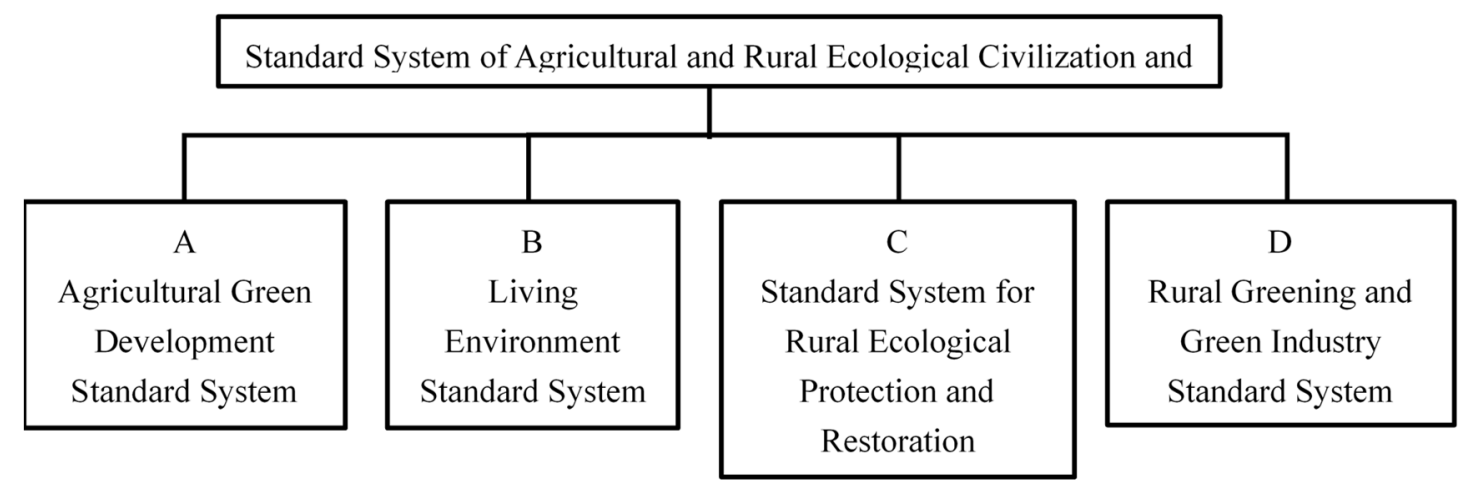

Fig.1 Structure of agricultural and rural ecological civilization and green development standard system

\subsection{Promote the deep integration of various industrial chains, stimulate and release the great endogenous force of rural development.}

Relying on the geographical advantages of rural areas in terms of nature and humanity, green agriculture can make use of local resources, strengthen the synergy between related industries, re-optimize the spatial layout and operation structure of agricultural industry chain, improve the market positioning accuracy of agricultural products and their supporting services through the implementation of market-oriented development orientation, refine the price range and enhance the premium ability, re-integrate the existing industrial chain in rural areas from a vertical perspective, and form a risk-sharing and benefit-sharing alliance development model $^{2}$. On this basis, around the promotion of green agriculture, we should cultivate leading enterprises with driving force and radiation force and absorb other new business entities such as major professional households, family farms and matrix cooperatives, so as to open up the docking channels from production, transportation to sales and management. This can not only further improve the production and operation efficiency of green agriculture and increase revenue channels, but also effectively avoid the blindness of production scale expansion and market delivery, minimize the potential economic risks faced by producers, operators and practitioners, and create a stable and healthy market pattern, so that the huge endogenous force of rural social self-hematopoietic and efficient development can be fully stimulated and released.

\subsection{Scientific development of agricultural resources and curbing the expansion of ecological destruction contribute to the sustainable development of rural society.}

How to balance the interaction between resource development, ecological protection and economic development has always been one of the primary issues to be considered and solved in the development of agricultural modernization. The gradual promotion and industrialization of green agriculture in rural areas, first of all, have scientifically coordinated the development of rural resources and environmental protection, changed the single production and operation mode of the small-scale peasant economy relying on land survival, and gradually replaced the abuse of pesticides and fertilizers by a cleaner and environmentally friendly new farming approach. It not only effectively improved the yield of food crops, but also helped to restore the production capacity of soil and curb the spread of land salinization and desertification. Especially with the further participation of biotechnology enterprises in the industrial operation of green agriculture, a large number of agricultural science and technology products with various varieties and rich functions have been put into production. Through the establishment of cooperative relations with relevant agricultural technology institutions and organizations, a large number of original high energy consumption and low-income production and operation modes have been effectively eliminated, so that the green, recyclable and efficient modern operation mechanism has been widely used. This undoubtedly conforms to the development concept of the development trend of the times and promotes the scientific transformation and sustainable development of the production and life mode of rural society.

\section{Opportunities and challenges faced by the industrialization transformation of green agriculture in the context of supply-side reform.}

\subsection{Relevant policies and systems provide strong support to improve the effectiveness of the transfer of various factors of production.}

Optimizing the agricultural industrial structure, promoting the quality and income of agricultural products, and driving the sustainable development of rural economy are the core essence and central goal of the supply-side structural reform. The industrialization development of 
green agriculture emphasizes the construction of a lowcarbon, green and efficient modern agricultural production and management system on the basis of scientific overall planning of resource development and environmental protection, so as to achieve the healthy, coordinated and long-term development of rural social economy by ensuring agricultural safety, stimulating market vitality and enhancing competitiveness. Therefore, the industrialization of green agriculture undoubtedly meets the basic requirements of the supply-side structural reform, so it has also received sufficient policy support and institutional guarantee. Therefore, we can take advantage of the opportunity of economic system reform and industrial integration, make use of the efficient circulation of various production factors such as land, labor, capital, technology, management system, cultivate regional leading enterprises with power and radiation, strengthen the linkage between various new business entities, and form an integrated industrial chain centered on green agriculture and docking various related industries, thus further strengthening the concept of resource sharing, complementary advantages and win-win development, and creating favorable conditions for the industrialization of green agriculture and the deep integration of modern science and technology promotion, cross-regional market expansion and social benefit acquisition.

\subsection{The overall technical level is low, the degree of industrial chain integration needs to be improved, and the market demand needs to be stimulated.}

While China's green agriculture is developing towards scale and standardization, due to the influence of single development concept, production and management system and other factors, the integration between green agriculture and supply-side structural reform still needs to be further improved. First of all, the current domestic green agriculture has a low degree of coordination with related and associated industries. It generally only establishes a relatively loose dialogue mechanism, lacks more specific and in-depth cooperation, and does not really form an integrated industrial chain. Secondly, for a long time, China 's local governments and enterprises have invested less in the research and development of green agricultural science and technology, and most of the existing technologies and equipment are relatively old, which has separated the convergence between the recycling of material energy and the application of reduction. Third, the current market capacity of China's green agriculture is small. Small and medium-sized enterprises occupy the main position, lack leading enterprises, and have weak leading effect on the latest production and consumption concepts ${ }^{3}$.

\section{Industrialization operation strategy of green agriculture transformation docking with supply-side reform}

\subsection{Building a healthy and coordinated market ecology and promoting the green transformation of production and life.}

Based on the goal of assisting supply-side structural reform and accelerating the transformation of green agriculture industrialization, rural local governments should strictly implement policies and systems such as territorial management of agricultural products, classification inspection, registration of producing areas and publicity of quality and safety inspection results in accordance with relevant national laws and regulations, so as to create a fair, transparent and orderly competitive environment for the market delivery and marketing of ecological agricultural products. At the same time, we should also focus on the promotion and promotion of the concept and mode of green development, to further optimize the existing distribution channels and networks of green agricultural products, to create a green agricultural products monopoly supply system, to guide enterprises and the people to truly understand and accept low carbon consciousness and green consumption behavior, to eliminate and abandon the development concept of high energy consumption, so as to promote the development trend of rural production and lifestyle towards health, environmental protection and sustainable development.

\subsection{To cultivate green agricultural industry with local characteristics and build agglomeration industrial chain.}

Relying on all kinds of local advantageous resources in rural areas, such as land, labor, natural and cultural landscape, with the policy support and institutional guarantee given by supply-side structural reform, starting from meeting the actual needs of agricultural economic system reform and rural social transformation, the development platform of green agricultural industrial park, entrepreneurship park and green agricultural science and technology complex is established to highlight the regional characteristics and cultural connotation, and gradually form a green agricultural concentration area with reasonable industrial layout, resource sharing and complementary, and industrial coordination and integration. On this basis, we should further strengthen the docking and integration between green agriculture and rural tourism, catering industry, transportation industry, cultural and creative industry, leisure and health industry, and vigorously cultivate leading enterprises, family farms, professional households, so as to create an open, complementary and interactive integrated industrial chain. 


\subsection{Promote low-carbon and efficient new agricultural technologies and improve the standardization of production.}

Based on meeting the requirements of the supply-side structural reform, the latest foreign green agricultural technology and equipment should be introduced reasonably, and the existing production and operation mode should be upgraded comprehensively. On the basis of reducing energy consumption, improving output and efficiency, and in accordance with the reality of China 's agricultural development, the promotion of green agricultural technology, the updating of fine agriculture, and the popularization of modern information and biotechnology should be taken as the main breakthrough points, so as to create a more innovative, efficient industrial form that meets the needs of rural economic development ${ }^{4}$. By adjusting the policy, optimizing the system and strengthening the management of the collaborative way to promote the development of China 's agriculture, rural production standards in line with the reality of the current stage of development, unified specification of agricultural production and processing technology, green packaging and other standards system, effectively improve the overall quality of green agricultural products, safe, healthy, high-quality green product output, guide the scientific transformation of rural production and lifestyle.

\subsection{Improve the special fund guarantee mechanism and accelerate the regional development of green agriculture.}

It is necessary to further improve the existing financial credit system, gradually improve the special financing mechanism by promoting the supply-side structural reform, and effectively increase the sources of investment and financing by creating a development fund support and guarantee mortgage platform, enriching the supply of financial products and services. At the same time, rural local governments should also reasonably reduce relevant taxes and fees and introduce various preferential policies for financial reduction and exemption. Particularly, it is necessary to strongly support the leading enterprises in the region to participate in the introduction and output of green agricultural technology and products, truly rely on the characteristics and advantages of rural society in location space and resources, and gradually form a cluster of green agricultural enterprise industrial chain around the planting and processing of agricultural products, so as to build an industrialization development pattern with regional characteristics and focus on independent innovation in an all-round way, and make green agriculture become an economic new format covering regional society.

\section{Conclusion}

According to effective docking supply-side structural reform, we should steadily promote low-carbon production, green management and scientific management of green agriculture, and truly generate a new form of organic integration of resource development, environmental protection and economic development.

\section{Acknowledgments:}

University Research Project of Inner Mongolia Education Department (NJSY 20214)

\section{Reference:}

1. MaLi. Study on the Development Strategy of Efficient Green Agriculture under the Background of Rural Revitalization [J]. agricultural economy, 2018(10):76-77.

2. Xiao Rong, Liu Xuelian, Liu Zhiling. Co-evolution mechanism and equilibrium analysis of internal populations of green system in agricultural industrial agglomeration area $[\mathrm{J}]$. jiangsu agricultural sciences, 2017(24):62.

3. Chen Zhonghua. The Value Chain Optimization Strategy of Agricultural Leading Enterprises under the Background of Supply Side Reform [J]. Commercial economy research, 2019(04): 127 .

4. Xiong Wei, Fu Zongping, Wang Peng. Promotion of Rural Energy Supply Side Reform under Green Environment Construction [J]. rural economy, 2017(12):19-20. 